Editorial

Ada Ávila Assunção ${ }^{1,2}$

\author{
${ }^{1}$ Departamento de Medicina Preventiva e \\ Social da Universidade Federal de Minas \\ Gerais. Belo Horizonte, MG, Brasil. \\ 2Pesquisadora Nível 1 do Conselho Nacional \\ de Desenvolvimento Científico e Tecnoló- \\ gico (CNPq). Consultora do Ministério da \\ Saúde no tema relacionado aos trabalha- \\ dores da saúde. Membro do Conselho \\ Editorial da RBSO. \\ Contato: \\ Ada Ávila Assunção \\ E-mail: \\ adavila@medicina.ufmg.br
}

\section{Revista Brasileira de Saúde Ocupacional - 40 anos}

\author{
Revista Brasileira de Saúde Ocupacional - 40 years
}

A Revista Brasileira de Saúde Ocupacional alcançou estabilidade no último período, firmando o seu objetivo de disseminar a produção de conhecimentos sobre saúde e segurança no trabalho. Construindo um novo ponto de vista no referido campo de conhecimento, o Conselho Editorial tem destacado em suas publicações as obras de autores que visam a identificar e a entender as relações entre saúde e trabalho, interessando também a elaboração e a avaliação das políticas de saúde do trabalhador em determinado momento e em diferentes instâncias da ação social.

A fim de evitar a estrutura arcaica adotada em alguns estilos editoriais de encadear artigos, buscou-se construir, pelo menos ao que se vê no Editorial do número 105-106, um modo de conceituação capaz de criar uma identidade da RBSO (EDITORIAL, 2003a). No número subsequente (107-108), o Editorial é claro quanto à feição científica da revista, como se vê na justificativa para a ampliação do Conselho Editorial: agregar qualidade à publicação, alargar o espectro temático, reforçar o perfil multidisciplinar que seria "fundamental para a abordagem científica" (EDITORIAL, 2003b, p. 5). Em 2005, o Editorial do número 111 desenvolve a ideia já acenada nas edições anteriores ao explicitar o objetivo de "difundir novas representações e dimensões sobre os conceitos e fenômenos que os expliquem melhor e que permitam ações preventivas efetivas" (JACKSON FILHO; BARREIROS, 2005, p. 3). Mudanças contundentes foram planejadas para embasar a qualificação da RBSO na Scientific Eletronic Library Online (SciELO).

Em seus 40 anos, a RBSO retratou o contexto político e econômico em que se dão os processos de trabalho e suas relações com a saúde. Depois de um período perpassado tanto por interrupção, quanto por irregularidade da publicação (Figura 1), a revista, em 2003, retomou suas edições com o seguinte Editorial (2003a, p. 5): "Este primeiro ano do novo governo brasileiro representou para a Fundacentro um ano de recuperação institucional”. Destacando a questão do meio ambiente, aquele Editorial continua: "[...] o desenvolvimento sócio-econômico também requer processos sustentáveis de trabalho [...]" (EDITORIAL, 2003a, p. 5).

Como tudo começou? A RBSO foi lançada em 1973, dois anos antes do governo instituir uma política de prevenção dos acidentes que tinham "manchado" o início daquela década. Quatro anos depois é aprovada a Lei oㅜ 6.514, de 22 de dezembro de 1977 (BRASIL, 1977), sobre segurança, higiene e medicina do trabalho. Em 1979, ocorreram as primeiras Semanas de Saúde do Trabalhador (SEMSAT), as quais fundamentaram a mobilização sindical relativa ao tema nos anos seguintes. 


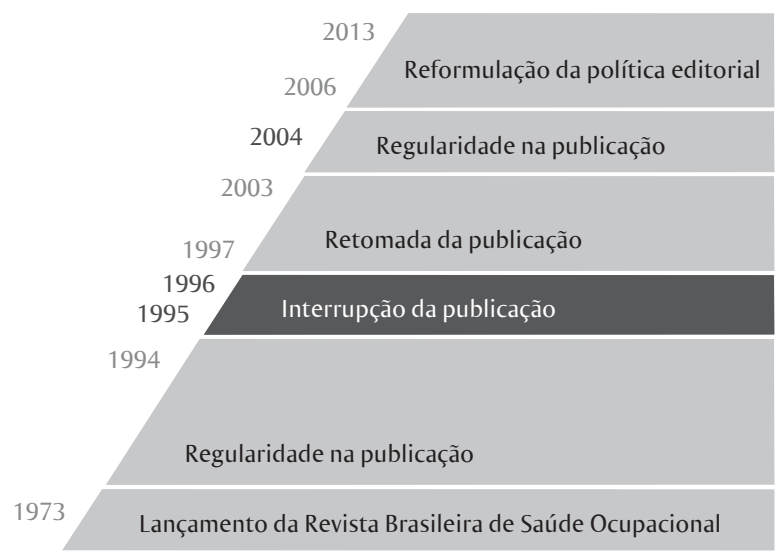

Figura 1 Linha do tempo da Revista Brasileira de Saúde Ocupacional

O Editorial do primeiro número da revista, elaborado por Gilson Luiz Vianna, à época secretário do Ministério do Trabalho e Previdência Social, apresenta na primeira linha: "O Governo do Presidente Médici traçou a seguinte diretriz: a meta é o homem" (VIANNA, 1973, p. 5). O Presidente da Fundacentro, Jorge Duprat Figueiredo, escreve: "Uma revista que represente o Brasil, seu progresso e a qualidade do seu desenvolvimento, como voltado fundamentalmente para o homem, visando à implantação de um moderno sistema econômico e social, dentro de uma sociedade aberta e livre" (FIGUEIREDO, 1973, p. 7). Mais à frente, um artigo cita o Plano Nacional de Valorização do Trabalhador e a Portaria Ministerial de 1972, que regulamenta a matéria. Vale a pena ler! A segunda capa deste primeiro número exibe um desenho do "trabalhador da cabeça aos pés": capacetes, máscaras, respiradores, protetores auriculares, óculos, aventais, luvas, mangas, calçados, porta eletrodos, filtros de luz, lentes e vidros... No final da mesma página, consta o endereço da empresa fabricante dos referidos equipamentos de proteção individual.

Durante os anos de 1995 e 1996, a RBSO não apareceu. Curioso! Segundo escreve Hobsbawn, o século XX foi breve: começou em 1914 com a primeira guerra e terminou em $1991 \mathrm{com}$ o fim da era soviética. Para o historiador, "o mundo perdeu suas referências e resvalou para a instabilidade e a crise" no terceiro quartil do breve século (HOBSBAWN, 1994, p. 393).

O período difícil da RBSO ocorre na última parte do século XX, aquela caracterizada por decomposição, incerteza e crise. Com a nova desigualdade global, "o mais barato ser humano é mais caro que uma máquina capaz de fazer o trabalho" (HOBSBAWN, 1994, p. 403). Os acontecimentos no final do breve século XX teriam trazido "perplexidade" e "impotência", tal como citam Minayo-Gomez e Lacaz (2005), para aqueles que estudavam e atuavam na área? É certeira a crítica dos autores no que se refere aos limites do modelo tradicional da saúde do trabalhador. Tal modelo desenvolvido para a abordagem da fábrica taylorista-fordista seria insuficiente para capturar "os efeitos mais nefastos do movimento mundial de reestruturação produtiva" (MINAYO-GOMEZ; LACAZ, 2005, p. 800). Ficou para trás, no breve século XX de Hobsbawn, abordar as relações saúde e trabalho como se fazia nos consultórios médicos das fábricas de Henry Ford?

A estabilidade da RBSO talvez tenha sido uma demonstração de que saímos do referido estado de perplexidade e impotência. Contudo, ainda enfrentamos desafios teórico-metodológicos e dilemas no âmbito da prática. As formas desorientadas e desagregadas da vida no século XXI estão articuladas às rápidas mudanças nas condições de trabalho, cujo caráter mudou profundamente. Apesar dos efeitos relacionados às inovações organizacionais e tecnológicas, desde 1980, a agenda sindical teve de adotar como tema central a manutenção do emprego em detrimento de ações específicas visando à proteção da saúde dos trabalhadores (DEPARTAMENTO INTERSINDICAL DE ESTATÍSTICA E ESTUDOS SOCIOECONÔMICOS, 2012).

Quase metade da população ocupada nas regiões metropolitanas brasileiras encontra-se na informalidade (DEPARTAMENTO INTERSINDICAL DE ESTATÍSTICA E ESTUDOS SOCIOECONÔMICOS, 2012). Quanto aos empregos formais, a maioria $(78,4 \%)$, em 2010, concentrou-se no setor de serviços, o qual foi responsável, em 2012, por 68,5\% do PIB brasileiro (BRASIL, 2013). Concomitantemente, o trabalho escravo ainda é realidade em várias regiões do país e as repercussões da escravidão remota ainda estão presentes no trabalho livre em um ou em outro ramo da produção. Quanto a ela, é Caio Prado Junior que esclarece sobre a força 
das barreiras que separam as classes no Brasil quando caracteres somáticos, no caso, a cor, agregam uma discriminação na estrutura social (PRADO JUNIOR, 2011). Os cargos de direção e gerência nas empresas são, predominantemente, ocupados por não negros. Nesse plano, agrega-se um diferencial de gênero: as mulheres negras vivenciam mais dificuldade de se inserir no mercado de trabalho, ocupam postos vulneráveis, sendo menor o rendimento médio por hora se comparado ao do homem assalariado não negro (DEPARTAMENTO INTERSINDICAL DE ESTATÍSTICA E ESTUDOS SOCIOECONÔMICOS, 2012).

Em que pese o crescente aumento da inserção feminina (independentemente de cor/raça) no mercado do trabalho, a taxa de desemprego das mulheres continua maior do que as dos homens. Em 2009, o trabalho doméstico foi o segundo setor de atividade que mais empregou mulheres nas regiões metropolitanas de Bahia, São Paulo e Distrito Federal. Continua menor a possibilidade de as mulheres ocuparem posições de mando superior quando comparada à situação dos homens (DEPARTAMENTO INTERSINDICAL DE ESTATÍSTICA E ESTUDOS SOCIOECONÔMICOS, 2012).

Adicionando aos dados citados anteriormente aqueles fornecidos pela Relação Anual de Informações Sociais (RAIS), torna-se claro o posicionamento da RBSO "em difundir novas representações e dimensões sobre os conceitos e fenômenos" (JACKSON FILHO; BARREIROS, 2005, p. 3). Segundo Veras et al. (2011), a RAIS informa que os desligamentos que se referem aos problemas de saúde do trabalhador (no caso, indicadores específicos como doenças profissionais) são quase nulos numericamente. A maior incidência de casos de afastamentos ocorre no grupo de doenças não relacionadas ao trabalho. Todavia, cresceu, entre 2006 e 2008, o número de trabalhadores expostos a agentes nocivos, o que dá direito à aposentadoria especial pelo Instituto Nacional do Seguro Social (INSS). A licença maternidade é a segunda causa de afastamento de maior relevância numérica (VERAS; PINTO; SANTOS, 2011).

A Organização Internacional do Trabalho - OIT (ORGANIZAÇÃO INTERNACIONAL DO TRABALHO, 2010) comemorou o Dia Mundial da Segurança e Saúde no Trabalho, em 28 de abril de 2010, enfatizando três grupos de problemas: as novas tecnologias e os novos processos de produção (nanotecnologias e biotecnologias); novas condições de trabalho (cargas de trabalho, intensificação das tarefas devido à restrição de efetivos, disparidades relacionadas à migração da força de trabalho, empregos em uma economia informal); formas emergentes de emprego (home work, contratos terceirizados, contratos temporários, banco de horas).

A OIT, à semelhança do exposto na linha do Editorial da RBSO (JACKSON FILHO; BARREIROS, 2005), assume a importância do aporte científico para compreender os novos e emergentes riscos profissionais cuja origem é atribuída às inovações técnicas e às mudanças sociais ou organizacionais (ORGANIZAÇÃO INTERNACIONAL DO TRABALHO, 2010). A tarefa é complexa, pois exigiria, nos dizeres de Morin (2010), a religação de saberes.

A leitura daqui a 40 anos destas linhas provocará que tipo de crítica e indignação do Conselho Editorial da revista? Podemos pensar sobre isso. Mas a tradicional estratégia retrospectiva que os historiadores utilizam pode ser mais confortável do que antever o futuro. Vamos a ele!

\section{Referências}

BRASIL. Ministério do Desenvolvimento, Indústria e Comércio Exterior. Panorama do Comércio Internacional de Serviços. Dados Coletados de 2012. Brasília:

Departamento de Políticas de Comércio e Serviços, 2013.

. Lei n⿳⺈ 6.514, de 22 de dezembro de 1977. Altera o Capítulo V do Título II da Consolidação das Leis do Trabalho, relativo à segurança e medicina do trabalho e dá outras providências. Diário Oficial [da] República Federativa do Brasil, Brasília, DF, 23 dez. 1977. Disponível em: <http://www.planalto.gov.br/ ccivil_03/leis/l6514.htm >. Acesso em: 30 dez. 2013.

DEPARTAMENTO INTERSINDICAL DE ESTATÍSTICA E ESTUDOS SOCIOECONÔMICOS. A situação do trabalho no Brasil na primeira década dos anos 2000. São Paulo: Dieese, 2012.
EDITORIAL. Revista Brasileira de Saúde Ocupacional, São Paulo, v. 28, n. 107-108, p. 5, 2003a.

EDITORIAL. Revista Brasileira de Saúde Ocupacional, São Paulo, v. 28, n. 105-106, p. 5, 2003b.

FIGUEIREDO, J. D. A informação como instrumento do progresso. Revista Brasileira de Saúde Ocupacional. São Paulo, v. 1, n. 1, p. 7, 1973.

HOBSBAWM, E. A era dos extremos: o breve século XX. São Paulo: Companhia das Letras, 1995.

JACKSON FILHO, J. M.; BARREIROS, D. Editorial. Revista Brasileira de Saúde Ocupacional. São Paulo, v. 30, n. 111, p. 3, 2005.

MINAYO-GOMEZ, C. ; LACAZ, F. A. C. Saúde do trabalhador: novas-velhas questões. Ciência \& Saúde Coletiva. Rio de Janeiro, v. 10, n. 4, p. 797-807, 2005. 
MORIN, E. Introdução às jornadas temáticas. In: . A religação dos saberes. Rio de Janeiro:

Bertrand Brasil, 2010. p. 13-23.

ORGANIZAÇÃO INTERNACIONAL DO TRABALHO.

Riscos emergentes e novas formas de prevenção num mundo de trabalho em mudança. Genebra, 2010.

PRADO JUNIOR, C. Formação do Brasil

contemporâneo. São Paulo: Companhia das Letras, 2011.
VERAS, M. E. P.; PINTO, M. G. P.; SANTOS, A. R. M. Sistemas de informação do Ministério do Trabalho e Emprego relevantes para a área de saúde e segurança no trabalho - RAIS, CAGED, SFIT. In: CHAGAS, A. M. R.; SALIM, C. A.; SERVO, L. M. S. Saúde e segurança no trabalho no Brasil: aspectos institucionais, sistemas de informação e indicadores. Brasília: Ipea, 2011.

VIANNA, G. L. A meta é o homem. Revista Brasileira de Saúde Ocupacional. São Paulo, v. 1, n. 1, p. 5, 1973. 